\title{
Refractory Myelofibrosis
}

National Cancer Institute

\section{Source}

National Cancer Institute. Refractory Myelofibrosis. NCI Thesaurus. Code C162425.

Myelofibrosis that is resistant to treatment. 